\title{
Data Papers
}

\section{The Agrodiversity Experiment: three years of data from a multisite study in intensively managed grasslands}

\author{
Ecological Archives E095-232
}

Laura Kirwan, ${ }^{1}$ John Connolly, Caroline Brophy, Ole Baadshaug, Gilles Belanger, Alistair Black, Tim Carnus, Rosemary Collins, Jure Čop, Ignacio Delgado, Alex De Vliegher, Anjo Elgersma, Bodil FrankowLindberg, Piotr Golinski, Philippe Grieu, Anne-Maj Gustavsson, Áslaug Helgadóttir, Mats Höglind, Olivier Huguenin-Elie, Marit Jørgensen, Žydré Kadžiuliené, Tor Lunnan, Andreas Lüscher, Päivi Kurki, Claudio Porqueddu, M.-Teresa Sebastia, Ulrich Thumm, David Walmsley, and John Finn

\begin{abstract}
Intensively managed grasslands are globally prominent ecosystems. We investigated whether experimental increases in plant diversity in intensively managed grassland communities can increase their resource use efficiency.

This work consisted of a coordinated, continental-scale 33-site experiment. The core design was 30 plots, representing 15 grassland communities at two seeding densities. The 15 communities comprised four monocultures (two grasses and two legumes) and 11 four-species mixtures that varied in the relative abundance of the four species at sowing. There were 1028 plots in the core experiment, with another 572 plots sown for additional treatments. Sites followed a protocol and employed the same experimental methods with certain plot management factors, such as seeding rates and number of cuts, determined by local practice. The four species used at a site depended on geographical location, but the species were chosen according to four functional traits: a fast-establishing grass, a slow-establishing persistent grass, a fast-establishing legume, and a slow-establishing persistent legume. As the objective was to maximize yield for intensive grassland production, the species chosen were all highyielding agronomic species.

The data set contains species-specific biomass measurements (yield per species and of weeds) for all harvests for up to four years at 33 sites. Samples of harvested vegetation were also analyzed for forage quality at 26 sites.

These data should be of interest to ecologists studying relationships between diversity and ecosystem function and to agronomists interested in sustainable intensification. The large spatial scale of the sites provides opportunity for analyses across spatial (and temporal) scales. The database can also complement existing databases and meta-analyses on biodiversityecosystem function relationships in natural communities by focusing on those same relationships within intensively managed agricultural grasslands.
\end{abstract}

Key words: agricultural grasslands; biodiversity; ecosystem function; forage quality; mixtures monocultures; overyielding; plant community; species biomass; yield.

The complete data sets corresponding to abstracts published in the Data Papers section of the journal are published electronically in Ecological Archives at http://esapubs.org/archive (the accession number for each Data Paper is given directly beneath the title).

Manuscript received 25 January 2014; revised 10 June 2014; accepted 11 June 2014. Corresponding Editor: W. K. Michener.

${ }^{1}$ Corresponding author. Waterford Institute of Technology, Cork Road, Waterford, Ireland. E-mail: laura.kirwan@outlook.com. See the full data paper in Ecological Archives for affiliations of other authors. 